\title{
Analisis SWOT Pembelajaran Daring Mahasiswa Kebidanan Pada Masa Pandemi Covid-19
}

\author{
Ni Wayan Sukma Adnyani*, Velintina Krisda Elvina \\ Prodi DIII Kebidanan Politeknik Kesehatan Kartini Bali \\ *Corresponding Author. Email: sukmaadnyani@gmail.com
}

\begin{abstract}
The purpose of this study was to analyze the effectiveness of online learning with a SWOT matrix analysis for Diploma III midwifery students during the Covid-19 pandemic at the Polytechnic of Health Kartini Bali. The method in this research is qualitative, with analysis using the SWOT matrix approach to formulate strategies to improve the quality of online learning for students. The research subjects were 15 representatives of Level I, II and III students. Collecting data using a questionnaire with a closed list of questions containing internal and external variables that affect learning. The results showed that from the results of the SWOT analysis, four alternative strategies were formulated, namely the Strategy Strength-Opportunities (SO), Weaknesses-Opportunities (WO), Strength-Threats (ST), and WeaknessesThreat (WT) which included quality improvement in terms of methods. learning (providing modules, elerning and video tutoral), infrastructure (internet quota), human resources (participant motivation) and related stakeholder commitment. So it can be concluded that SWOT analysis on online learning can be used as input in improving the quality of learning for organizers, students and institutions in supporting the success of online learning during the Covid-19 periodat the Polytechnic of Health Kartini Bali.
\end{abstract}

\begin{abstract}
Abstrak: Tujuan dari penelitian ini adalah untuk menganalisis efektivitas pembelajaran daring dengan analisa matriks SWOT pada mahasiswa D III Kebidanan pada masa pandemi Covid-19 di Politeknik Kesehatan Kartini Bali. Metode pada penelitian ini adalah kualitatif, dengan analisa menggunakan pendekatan matriks SWOT untuk merumuskan strategi peningkatan kualitas pembelajaran daring pada mahasiswa. Subjek penelitian adalah perwakilan mahasiswa Tingkat I, II dan III sejumlah 15 orang. Pengumpulan data menggunakan kuesioner dengan daftar pertanyaan tertutup yang berisi variabel internal dan eksternal yang mempengaruhi pembelajaran. Hasil penelitian menunjukan bahwa dari hasil analisis SWOT diperoleh empat rumusan alternatif strategi yaitu Strategi Strength-Opportunities (SO), Weaknesses-Opportunities (WO), Strength-Threats (ST), dan Weaknesses-Threat (WT) yang mencakup peningkatan kualitas dari segi metode pembelajaran (pemberian modul, $e$ learning dan video tutorial), sarana prasarana (kuota internet), SDM (motivasi peserta) dan komitmen stakeholder yang terkait. Sehingga dapat disimpulkan bahwa analisis SWOT pada pembelajaran daring dapat dijadikan sebagai masukan dalam peningkatan kualitas pembelajaran bagi penyelenggara, peserta didik dan Institusi dalam menunjang keberhasilan pembelajaran daring pada masa Covid-19 di Politeknik Kesehatan Kartini Bali.
\end{abstract}

\section{Article History}

Received: $19-10-2020$

Revised: 02-03-2021

Accepted: 21-04-2021

Published: 07-06-2021

\section{Key Words:}

SWOT Analysis,

Online Learning,

Covid-19.

\section{SejarahArtikel}

Diterima: 19-10-2020

Direvisi: 02-03-2021

Disetujui: 21-04-2021

Diterbitkan: 07-06-2021

\section{Kata Kunci:}

Analisis SWOT, Pembelajaran Daring, Covid-19.

How to Cite: Sukma Adnyani, N., \& Krisda Elvina, V. (2021). Analisis SWOT Pembelajaran Daring Mahasiswa Kebidanan Pada Masa Pandemi Covid-19. Jurnal Kependidikan: Jurnal Hasil Penelitian dan Kajian Kepustakaan di Bidang Pendidikan, Pengajaran dan Pembelajaran, 7(2), 437-445. doi:https://doi.org/10.33394/jk.v7i2.3027 


\section{Pendahuluan}

Pandemi Covid-19 saat ini sedang banyak dibicarakan dan menimbulkan berbagai macam persepsi, kekhawatiran dan berbagai upaya dalam pencegahan wabah penyakit tersebut. Lingkup pendidikan merupakan lingkup yang memiliki dampak besar dari adanya pandemi ini. Penyesuaian terhadap metode pembelajaran berbasis online merupakan tantangan besar bagi dosen dan mahasiswa.Penelitian yang dilakukan oleh (Zhang, D.,et al, 2004) menyatakan penggunaan internet dan teknologi multimedia mampu merombak cara penyampaian pengetahuan dan menjadi alternatif pada pembelajaran tatap muka yang biasa dilaksanakan dalam kelas.

World Health Organizazion (WHO) memberikan himbauan untuk menghentikan kegiatan yang menimbulkan perkumpulan masa. Perkuliahan dilaksanakan dengan skenario yang mampu mencegah kontak secara fisik antara penyelenggara pendidikan dan peserta didik maupun antar peserta didik itu sendiri (Firman, F., \& Rahayu, 2020). Adapun bentuk pembelajaran yang dapat digunakan sebagai solusi di masa pandemi yaitu pembelajaran daring. Pembelajaran daring sendiri merupakan pembelajaran dengan menggunakan jaringan internet dengan aksesibilitas, konektivitas, fleksibilitas dan kemampuan untuk memunculkan berbagai jenis interaksi pembelajaran. Perguruan tinggi pada masa WFH perlu melaksanakan penguatan pembelajaran secara daring (Darmalaksana, 2020). Dimana pembelajaran daring dibutuhkan dalam pembelajaran di era revolusi industri 4.0 (Pangondian, R. A., Santosa, P. I., \& Nugroho, 2019).

Adapun hasil penelitian terkait menyatakan bahwa dengan pembelajaran daring membawa beberapa manfaat diantaranya mahasiswa tidak terkendala waktu dan tempat, mereka dapat mengikuti perkuliahan dari rumah masing-masing maupun dari tempat dimana saja. Adanya pembelajaran daring, dosen dapat memberikan kuliah melalui kelas-kelas virtual yang tidak terikat ruang dan waktu (Ali Sadikin, 2020). Penelitian yang dilakukan oleh Sun,et al., (2014) menyatakan bahwa fleksibilitas waktu, metode belajar dan tempat dalam pembelajaran daring berpengaruh terhadap kepuasan mahasiswa dalam pembelajaran (Sun, 2014). Penelitian lain menyatakan ketiadaan penghambat fisik serta batasan ruang dan waktu menyebabkan peserta didik lebih nyaman dalam berkomunikasi sehingga diharapkan adanya pembelajaran daring dapat meningkatkan interaksi antara dosen dan siswa dalam berdiskusi serta membuat suasana pembelajaran yang menyenangkan (Sun, 2014). Namun adapula tantangan yang dihadapi dalam perkuliahan daring yaitu kebutuhan akan akses internet merupakan modal utama baik siswa maupun dosen dalam menunjang kelancaran pembelajaran daring. Penelitian yang dilakukan Iskandar, dkk (2020) menyatakan kendala mahasiswa keperawatan dalam kuliah daring 39,9\% karena jaringan dan 37,8\% karena kuota internet (Iskandar, Syarifah Masthura, 2020).

Politekik kesehatan Kartini Bali merupakan Perguruan Tinggi vokasi di bidang kesehatan dimana mahasiswa tentunya akan sering bersentuhan atau berhadapan dengan pasien dalam praktiknya. Direktur Politeknik Kesehatan Kartini Bali dengan mengikuti himbauan dari Pemerintah Pusat telah mengadakan pembelajaran jarak jauh (daring) sejak Maret 2020 dan mengevaluasi kembali sampai kondisi dinyatakan stabil untuk melakukan perkuliahan tatap muka. Adanya pembelajaran daring pada masa pandemi Covid-19 dan new normal diharapkan dapat berjalan efektif dan memberikan manfaat bagi dosen dan mahasiswa, sehingga kompetensi mahasiswa dapat tercapai. Untuk mengukur efektifitas pembelajaran daring, dapat dilakukan dengan menerapkan analisa Strength Weaknesse Opportunities Threats (SWOT) yang sebagai rekomendasi dan masukan bagi peningkatan mutu pendidikan. Adapun tujuan dari penelitian ini adalah untuk menganalisis efektivitas 
pembelajaran daring dengan analisa SWOT pada mahasiswa D III Kebidanan pada masa pandemi Covid-19 di Politeknik Kesehatan Kartini Bali.

\section{Metode Penelitian}

Pendekatan penelitian yang digunakan adalah penelitian kualitatif dengan metode analisa matriks SWOT (Rangkuti, 2006). Populasi terjangkau dalam penelitian ini adalah mahasiswi kebidanan tingkat I, II \& III yang bersedia menjadi responden. Sampel yang diikutsertakan dalam penelitian ini akan menggunakan tehnik Probability Sampling dengan jenis Purposive Sampling yaitu teknik sampling yang menggunakan kriteria yang telah dipilih oleh peneliti dalam memilih sampel. Kriteria pemilihan sampel dipilih berdasarkan kriteria inklusi yaitu: mahasiswi D III kebidanan yang bersedia menjadi responden dan dalam keadaan sehat, sehingga jumlah sample dalam penelitian ini adalah 15 responden. Mahasiswa diberikan kuesioner yang berisi pernyataan untuk menggali informasi mengenai aspek SWOT dalam pembelajaran daring. Kuesioner diberikan kepada perwakilan mahasiswa dengan aplikasi google form. Data yang diperoleh kemudian diolah dan dianalisis menggunakan pendekatan matrik SWOT. Pengolahan diawali dengan mengidentifikasi jawaban responden dan dikelompokkan ke masing-masing aspek aspek SWOT yaitu kekuatan, kelemahan, peluang dan ancaman. Kemudian hasil identifikasi dimasukan ke Matriks SWOT untuk dianalisis.

\section{Hasil Penelitian dan Pembahasan}

Penelitian ini dilakukan di Institusi Politeknik Kesehatan Kartini Bali dengan sampel adalah mahasiswa D III Kebidanan. Pembelajaran daring telah dilaksanakan sejak pandemi Covid-19. Responden diambil dari perwakilan mahasiswa tingkat I, II dan III sejumlah 15 responden. Data diperoleh dari hasil jawaban responden yang direkap kemudian diidentifikasi dan dikelompokan menjadi empat aspek yaitu : kekuatan, kelemahan, peluang dan ancaman. Dibawah ini merupakan tabel penilaian untuk masing-masing kriteria pada Matriks SWOT yaitu :

Tabel 1. Kriteria Kriteria Matriks SWOT

\begin{tabular}{|c|c|c|}
\hline Internal & Strengths $(\mathrm{S})$ & Weaknesses (W) \\
\hline & $\begin{array}{l}\text { 1. Mahasiswa dapat dengan mudah } \\
\text { berdiskusi kepada dosen bila } \\
\text { mengalami hambatan dalam } \\
\text { pembelajaran melalui daring. } \\
\text { 2. Mahasiswa mulai terbiasa dengan } \\
\text { penggunaan teknologi/aplikasi } \\
\text { yang ada saat pembelajaran } \\
\text { daring } \\
\text { 3. Mahasiswa dapat mengikuti } \\
\text { pembelajaran daring dengan } \\
\text { waktu yang fleksibel. } \\
\text { 4. Mahasiswa dapat membagi } \\
\text { waktu perkuliahan dengan } \\
\text { melakukan aktifitas fisik seperti } \\
\text { berolahraga guna menjaga } \\
\text { imunitas tubuh. } \\
\text { 5. Selama pandemi Covid-19 dan } \\
\text { perkuliahan daring mahasiswa } \\
\text { dapat tetap menjaga kesehatan } \\
\text { tubuh dengan konsumsi makanan } \\
\text { yang bergizi. }\end{array}$ & $\begin{array}{l}\text { 1. Mahasiswa menemukan kesulitan } \\
\text { dalam menemukan materi yang } \\
\text { sesuai dan tidak memiliki waktu } \\
\text { cukup untuk membaca saat } \\
\text { perkuliahan daring. } \\
\text { 2. Rasa malas dan jenuh merupakan } \\
\text { salah satu penghambat dalam } \\
\text { pembelajaran daring. } \\
\text { 3. Perkuliahan daring memerlukan } \\
\text { persiapan yang lebih banyak } \\
\text { seperti kuota, laptop dan jaringan } \\
\text { internet yang stabil dibanding } \\
\text { kuliah tatap muka. } \\
\text { Mahasiswa merasa bosan bila } \\
\text { metode pembelajaran yang } \\
\text { diberikan sama. } \\
\text { Mahasiswa merasa pembelajaran } \\
\text { daring kurang meningkatkan } \\
\text { motivasi mahasiswa. }\end{array}$ \\
\hline
\end{tabular}




\section{Opportunities (O)}

1. Orangtua mendukung pembelajaran daring yang diberikan kepada mahasiswa selama pandemi Covid-19

2. Melatih mahasiswa lebih disiplin dengan waktu

3. Dengan pembelajaran daring mahasiswa tetap dapat berinteraksi dan adanya timbal balik dengan dosen.

4. Pembelajaran daring dengan pemberian video tutorial dalam pembelajaran lab dapat membantu mahasiswa dalam pemahaman teori dan praktek.

\section{Threats (T)}

1. Mahasiswa merasakan kesulitan berkonsentrasi dan suasana rumah kurang mendukung saat pembelajaran daring.

2. Kondisi ekonomi keluaga yang kurang stabil saat pandemi COVID-19 berpengaruh terhadap pembelajaran daring.

3. Institusi kurang memfasilitasi dalam memberikan kemudahan dalam perkuliahan daring.

4. Lokasi yang jauh dari kampus atau di kampung menyulitkan mahasiswa dalam memperoleh signal yang baik saat pembelajaran daring

5. Mahasiswa merasa lingkungan rumah di daerah /desa kurang menunjang dalam pembelajaran daring

\section{Strategi (S-O)}

1. Peningkatan kompetensi Mahasiswa dan Dosen dengan penggunakan media daring.

2. Efektivitas sarana berinteraksi antara dosen dan mahasiswa untuk lebih leluasa dalam bertukar pikiran atau berdiskusi.

3. Mengoptimalisasi pemahaman mahasiswa dalam kegiatan praktikum dengan sarana video tutorial

4. Waktu yang fleksibel dalam perkuliahan sehingga dapat lebih mengatur waktu

\section{Strategi (W-O)}

1. Meningkatkan komitmen dukungan dinas pendidikan dan pimpinan Institusi untuk memfasilitasi aksesibilitas internet bagi dosen dan mahasiswa

2. Meningkatkan kualiatas media pembelajaran dan metode pembelajaran daring agar dikemas lebih menarik dan tidak monoton.

3. Dosen pembimbing akademik (PA) dapat berperan dalam melakukan pendekatan dan evaluasi jalannya kuliah daring pada mahasiswa, serta memberikan dukungan bila mahasiswa mengalami hambatan atau menurunya minat belajar.

\section{Strategi (S-T)}

1. Menggeser mindset mahasiswa terkait pembelajaran yang biasanya tatap muka berubah menjadi daring.

2. Menumbuhkan kuliah daring guna menunjang kelancaran pembelajaran.

\section{Strategi (W-T)}

1. Membekali dosen dalam menyiapkan pengembangan aplikasi daring yang lebih menarik dan efektif bagi mahasiswa.

2. Melakukan kerjasama dengan dinas terkait dan penyedia layanan internet (provider) dalam solusi aksesibilitas Internet bagi dosen dan mahasiswa yang berada di lokasi yang terkendala Internetnya.

\section{Pembahasan}

\section{1) Analisis SWOT}

Berdasarkan Analisis SWOT yang terdiri dari kekuatan dan kelemahan internal serta peluang dan ancaman eksternal yang ada, diperoleh empat selft alternatif strategy yang dapat dirumuskan sebagaia berikut : 


\section{a) Strategi Strengths - Opportunities}

Berdasarkan strategi Strengths-Opportunities, yaitu menggunakan kekuatan yang dimiliki untuk meraih peluang yang ada. Adapun langkah-langkah yang dapat dilakukan diantaranya:

Pertama, peningkatan kompetensi dosen dan mahasiswa dalam penggunaan media daring. Saat ini Kementrian Pendidikan dan Kebudayaan telah memberikan fasilitas pembelajaran daring melalui website Kemendikbud yaitu SPADA (Sitem Pembelajaran daring Indonesia) yang bertujuan memberikan peluang bagi mahasiswa dari satu PT tertentu untuk dapat mengikuti suatu mata kuliah bermutu dari PT lain yang diakui. SPADA juga menyediakan materi dan pelatihan bagi dosen dalam memberikan metode pembelajaran daring yang efektif dan menarik, sehingga diharapkan dapat memperlancar proses kuliah daring dan memberikan sebuah manfaat bagi bersama khususnya dalam dunia pendidikan. Selain website yang disediakan pemerintah, terkait peningkatan kompetensi belajar penggunaan model e-learning dan google classroom meningkatkan motivasi belajar mahasiwa. Hal ini sejalan dengan penelitian yang dilakukan oleh (Daniati, Bambang Ismanto, 2020) dimana mahasiswa lebih tertarik dengan pembelajaran dengan memadukan penggunaan aplikasi teknologi.

Kedua, efektivitas sarana berinteraksi antara dosen dan mahasiswa untuk lebih leluasa dalam bertukar pikiran atau berdiskusi.Mengikuti pembelajaran dirumah membuat mahasiwa tidak merasakan tekanan psikologis dari teman sebayanya yang terkadang mereka rasakan saat kuliah tatap muka. Ketidakhadiran dosen secara langsung juga mempengaruhi mahasiswa merasa tidak canggung untuk mengemukakan pendapatnya (Ali Sadikin, 2020). Penelitian lain menyatakan ketiadaan penghambat fisik serta batasan ruang dan waktu menyebabkan peserta didik lebih nyaman dalam berkomunikasi sehingga diharapkan adanya pembelajaran daring dapat meningkatkan interaksi antara dosen dan siswa dalam berdiskusi serta membuat suasana pembelajaran yang menyenangkan (Sun, 2014).

Ketiga, mengoptimalkan pemahaman mahasiswa dalam kegiatan praktikum dengan sarana video tutorial, pada masa pandemi Covid-19 untuk mengoptimalkan pembelajaran praktikum laboratorium tetap berjalan sesuai waktunya, mahasiswa bekali dengan pembelajaran melalui video tutorial yang dibuat langsung oleh dosen pengampu mata kuliah. Hal ini dilakukan untuk mengoptimalkan dan menyamakan pemahama praktik yang sesuai daftar tilik serta menghindari mahasiswa memperoleh sumber yang tidak sesuai. Dosen juga bisa memberikan refrensi atau rujukan video yang sesuai buku refrensi, sehingga mahasiswa dapat mempelajari video sendiri dirumah dengan alat sederhana yang dimiliki.

Keempat, yaitu waktu yang fleksibel dalam perkuliahan daring, berdasarkan penelitian yang dilakukan Ali Sadikin, dkk (2020) secara keseluruhan mahasiswa puas dengan pembelajaran yang fleksibel. Mahasiswa tidak terkendala waktu dan tempat dimana mereka dapat mengikuti perkuliahan dari rumah masing-masing maupun dari tempat dimana saja. Adanya pembelajaran dariang, dosen dapat memeberikan kuliah melalui kelas-kelas virtual yang tidak terikat ruang dan waktu (Ali Sadikin, 2020). Kondisi ini tentunya membuat mahasiswa secara bebas memilih tugas mana yang harus dikerjakan terlebih dahulu dan dapat membagi waktu kuliah dengan pekerjaan rumah dengan baik. Penelitian lain yang dilakukan oleh Sun,et al., (2014) menyatakan bahwa fleksibilitas waktu, metode belajar dan tempat dalam pembelajaran daring berpengaruh terhadap kepuasan mahasiswa dalam pembelajaran (Sun, 2014).

\section{b) Strategi Weaknesses - Opportunities}

Pertama, meningkatkan komitmen dukungan Pemerintah khususnya dinas pendidikan dan pimpinan Institusi untuk memfasilitasi aksesibilitas internet bagi dosen dan mahasiswa. 
Rusdiana dan Nugroho (2020) menyebutkan dukungan perguruan tinggi dan dosen menjadi aspek penting dalam mendukung keberhasilan pembelajaran daring (Rusdiana, E., \& Nugroho, 2020). Dukungan perguruan tinggi dalam menyediakan sarana prasarana salah satunya yaitu memfasilitasi aksesibilitas internet juga memiliki peran yang penting, mengingat WFH mengalami perpajangan sampai akhir Desember 2020 ini, sehingga pembelajaran daring pun akan terus berlangsung. Kebutuhan akan akses internet merupakan modal utama baik siswa maupun dosen dalam menunjang kelancaran pembelajaran daring. Penelitian yang dilakukan Iskandar, dkk (2020) menyatakan kendala mahasiswa keperawatan dalam kuliah daring 39,9\% karena jaringan dan 37,8\% karena kuota internet (Iskandar, Syarifah Masthura, 2020). Untuk mengatasi kendala akses internet tersebut, Institusi berkoordinasi dengan Kemendikbud dalam upaya pemenuhan kebutuhan akan kuota internet. Bulan September 2020 dosen dan mahasiswa telah menerima kuota internet 50 GB bagi semua provider yang termasuk kuota belajar dan video conference sehingga mahasiswa tidak terkendala lagi dengan keterbatasan kuota.

Kedua, yaitu meningkatkan kualiatas media pembelajaran dan metode pembelajaran daring agar dikemas lebih menarik dan tidak monoton. Dalam hal ini dosen sebagai fasilitator pembelajaran tentunya memiliki peran utama dalam mengemas dan menyajikan materi yang menarik bagi mahasiswa. Masukan dari mahasiswa terhadap pembelajaran daring yang sudah dilakukan bisa menjadi bahan masukan dan perbaikan. Selain materi terkait waktu penyelenggaraan kuliah daring juga perlu diperhatikan, dimana lemahnya pengawasan dosen menyebabkan tidak terpantaunya aktifitas mahasiswa.Sehingga penting untuk melaksanakan pembelajaran daring dalam waktu yang tidak lama,mengingat mahasiswa sulit mempertahankan konsentrasi apabila perkuliahan daring dilaksanakan lebih dari satu jam (Khan, 2012).

Terkait penggunaan aplikasi, dosen juga penting untuk mempertahankan kualitas materi yang diberikan agar tetap up to date dan sesuai dengan evidence based. Agar pembelajaran tidak monoton mahasiswa bisa dilibatkan dalam pembelajaran berbasis critical thinking dimana mahasiswa diberikan tugas utk menganalisa suatu kasus kebidanan dan mengaitkan dengan jurnal-jurnal yang sesuai.Adanya inovasi dari dosen diharapkan kuliah daring dapat berjalan sesuai dengan harapan dan terciptanya sebuah pendidikan tinggi dengan suatu lingkungan belajar modern (Huda, M., Maseleno, A., Teh, K. S., Don, A. G., Basiron, B., Jasmi, K. A.Ahmad, 2018).

Ketiga, pembimbing akademik (PA) melakukan pendekatan dan evaluasi jalannya kuliah daring pada mahasiswa, serta memberikan dukungan bila mahasiswa mengalami hambatan atau menurunya minat belajar. Pembelajaran daring memiliki tantangan khusus, lokasi yang terpisah dan rentang waktu yang panjang dalam pembelajaran dirumah menyebabkan dosen tidak dapat mengawasi secara langsung kegiatan mahasiswa selama proses pembelajaran. Aspek psikologis peserta didik juga merupakan aspek yang perlu mendapatkan perhatian. Adanya pembimbing akademik (PA) tentunya dapat membantu mengevaluasi jalannya kuliah daring, terkait manfaat yang dirasakan ataupun hambatannya. Adanya dukungan dosen diharapkan mampu menumbuhkan kemandirian belajar dan memunculkan tanggung jawab dan otonomi dalam belajar (Kuo, Y. C., Walker, A. E., Schroder, K. E. E., \& Belland, 2014).

\section{c) Strategi Strengths - Threats}

Pertama, menggeser mindset mahasiswa terkait pembelajaran yang biasanya tatap muka berubah menjadi daring. Seiring berjalannya waktu perkuliahan daring yang awalnya awam sampai menjadi sebuah kewajiban bagi mahasiswa di masa new normal ini. Dukungan perguruan tinggi dalam menyediakan sarana dan prasarana, serta dosen menyiapkan materi ajar yang sesuai dengan pembelajaran maka mahasiswa akan terbiasa dengan perubahan 
sistem belajar dari tatap muka menjadi daring sehingga dapat membentuk sebuah mindset yang positif. Dianjurkan bahwa belajar daring bukan suplemen yang hanya memberikan manfaat tambahan (Holland, 2019). Namun segala sumber daya dikerahkan guna terciptanya pendidikan daring yang menjadi arus utama pendidikan tahun 2025 (Palvia, S., Aeron, P., Gupta, P., Mahapatra, D., Parida, R., Rosner, R., \& Sindhi, 2018)

Kedua, yaitu menumbuhkan kesadaran mahasiswa akan pentingnya kuliah daring guna menunjang kelancaran pembelajaran. Berdasarkan penelitian yang dilakukan Nurhasanah dan Sobandi (2016) menyatakan bahwa minat belajar merupakan determinan dari hasil belajar mahasiswa sehingga minat belajar ini harus dipertahankan (Nurhasanah, S., \& Sobandi, 2016). Kesadaran ini tentunya menjadi faktor penentu kelancaran pembelajaran daring. Selain kesadaran terkait manfaat kuliah daring, dosen juga perlu menumbuhkan kesadaran pada mahasiswa dengan pembelajaran daring keberadaan dosen dan mahasiswa yang berada di tempat berbeda selama pembelajaran dapat menghilangkan kontak fisik dan mampu mendorong munculnya perilaku social distancing, dimana social distancing sebagai solusi yang baik untuk mencegah penyebaran Covid-19 (Stein, 2020).

\section{d) Strategi Weaknesses - Threats}

Wicaksono (2021) menyatakan bahwa penerapan pembelajaran daring tidak seharusnya disikapi dengan skeptis walau dalam penerapannya memerlukan perlakuakn khusus secara kontekstual (Wicaksono, 2012). Berdasarkan strategi Weaknesses-Threats, strategi yang dapat digunakan untuk mengatasi kelemahan dan ancaman yang ada. Adapun langkah-langkah yang dapat dilakukan diantaranya:

Pertama yaitu membekali dosen dalammenyiapkan pengembangan aplikasi daring yang lebih menarik dan efektif bagi mahasiswa. Pelaksanaan pembelajaran daring harus diimbangi dengan pemeliharaan dan pengembangan aplikasi yang uptodate dan responsive terhadap setiap masukan dari mahasiswa, sehingga aplikais yang digunakan menjadi lebih menarik dan user friendly (Eni Susilawati, 2016). Semakin panjang waktu pelaksanaan kuliah daring dilakukan, semakin meningkat tantangan bagi dosen untuk menyediakan media pembelajaran dengan berbagai inovasi. Salah satunya dosen dapat memberikan modul sebagai bahan mahasiswa belajar mandiri dirumah dan jadwal yang berisi batas waku tugas dikerjakan. Hal ini dapat membantu melatih kemandirian dan kedisiplinan mahasiswa. Hal ini sejalan dengan penelitian yg dilakukan oleh (Fitriyani, Irfan Fauzi, 2020) yang menyatakan kemandirian mahasiswa dalam menyelesaikan tugas-tugas yang diberikan dosen sangat baik, apabila dalam pembelajaran media pembelajaran seperti modul juga dilengkapi.

Kedua yaitu bekerjasama dengan Pemerintah terkait dan penyedia layanan internet (provider) dalam solusi aksesibilitas Internet bagi dosen dan mahasiswa yang berada di lokasi yang terkendala Internetnya. Untuk menyiasati kondisi ini, bagi mahasiswa yang tinggal di daerah terpencil dan terkendala internet yaitu mencari wilayah-wilayah tertentu yang dapat terjangkau akses internet dan bisa ditambahkan dengan metode pembelajaran melalui pemberian video yang dibuat dosen yang bisa diakses secara offline oleh mahasiswa, sehingga memudahkan mahasiswa belajar ulang materi yang telah diberikan.

\section{Kesimpulan}

Kesimpulan yang dapat diperoleh dari hasil penelitian ini antara lain adalah : (1) Strategi Strength-Opportunities, meliputi: peningkatan kompetensi dosen dan mahasiswa dalam penggunakan media daring, meningkatkan efektivitas sarana berinteraksi antara dosen dan mahasiswa untuk lebih leluasa dalam bertukar pikiran atau berdiskusi, dan mengoptimalkan pemahaman mahasiswa dalam kegiatan praktikum dengan sarana video tutorial. (2) Strategi Weaknesses-Opportunities, meliputi : meningkatkan komitmen dukungan dinas pendidikan 
dan pimpinan Institusi untuk memfasilitasi aksesibilitas internet bagi dosen dan mahasiswa, meningkatkan kualiatas media pembelajaran dan metode pembelajaran daring agar dikemas lebih menarik dan tidak monoton dan pembimbing akademik melakukan pendekatan dan evaluasi jalannya kuliah daring pada mahasiswa, serta memberikan dukungan bila mahasiswa mengalami hambatan atau menurunya minat belajar.(3) Strategi StrengthsThreats, meliputi : Menggeser mindset mahasiswa terkait pembelajaran yang biasanya tatap muka berubah menjadi daring dan Menumbuhkan kesadaran mahasiswa akan pentingnya kuliah daring guna menunjang kelancaran pembelajaran. (4) Strategi Weaknesses-Threats, meliputi:membekali dosen dalammenyiapkan pengembangan aplikasi daring yang lebih menarik dan efektif bagi mahasiswa dan bekerjasama dengan dinas pendidikan dan penyedia layanan internet (provider) dalam solusi aksesibilitas Internet bagi dosen dan mahasiswa yang berada di lokasi yang terkendala Internetnya.

\section{Saran}

Adapun saran berdasarkan hasil penelitian ini yakni bagiPerguruan tinggi agar pembelajaran daring dapat menjadi salah satu solusi dalam metode pembelajaran yang ada pada masa pandemi Covid-19 dan adaptasi kebiasaan baru. Bagi dosen secara praktis berbagai peningkatan penyesuaian wajib dilakukan guna menjaga kualitas dan kuantitas pembelajaran, sehingga dukungan institusi terkait dalam memfasilitasi pembelajaran daring, kompetensi dosen sebagai fasilitator dalam kuliah daring dan motivasi mahasiswa dalam pembelajaran daring terus ditingkatkan serta dipertahankan. Bagipeneliti selanjutnya hasil penelitian ini dapat dijadikan masukan dan refrensi dalam evalusi pembelajaran daring yang sudah berlangsung serta terkait optimalisasi sistem pembelajaran daring dalam aspek yang lebih luas.

\section{Daftar Pustaka}

Ali Sadikin, A. H. (2020). Pembelajaran Daring di Tengah Wabah Covid-19. Biodik: Jurnal Ilmiah Pendidikan Biologi, 6(2), 214-224. doi:https://doi.org/10.22437/bio.v6i2.9759

Daniati, D., Ismanto, B., \& Luhsasi, D. (2020). Upaya Peningkatan Motivasi dan Hasil Belajar Mahasiswa dengan Penerapan Model Pembelajaran E-Learning Berbasis Google Classroom pada Masa Pandemi Covid-19. Jurnal Kependidikan: Jurnal Hasil Penelitian dan Kajian Kepustakaan di Bidang Pendidikan, Pengajaran dan Pembelajaran, 6(3), 601-608. doi:https://doi.org/10.33394/jk.v6i3.2642

Darmalaksana, W. (2020). WhatsApp Kuliah Mobile. Fakultas Ushuluddin UIN Sunan Gunung Djati Bandung.

Eni Susilawati. (2016). ANALISIS SWOT PENYELENGGARAAN DIKLAT ONLINE TEKNOLOGI INFORMASI DAN KOMUNIKASI (TIK) BAGI GURU. Jurnal Pendidikan Dan Kebudayaan, 1(3), 349-364.

Firman, F., \& Rahayu, S. (2020). Pembelajaran Online di Tengah Pandemi Covid-19. Indonesian Journal of Educational Science (IJES), 2(2), 81-89.

Holland, A. A. (2019). Effective principles of informal online learning design: A theory building metasynthesis of qualitative research. Computers \& Education.

Huda, M., Maseleno, A., Teh, K. S., Don, A. G., Basiron, B., Jasmi, K. A.Ahmad, R. (2018). Understanding Modern Learning Environment (MLE) in Big Data Era. International Journal of Emerging Technologies in Learning (IJET). 
Iskandar, Syarifah Masthura, C. O. (2020). PENERAPAN SISTEM PEMBELAJARAN DARING PADA MAHASISWA KEPERAWATAN UNIVERSITAS ABULYATAMA. Jurnal Dedikasi Pendidikan, 4(2), 323-332. Retrieved from http://jurnal.abulyatama.ac.id/index.php/dedikasi

Khan, S. (2012). The One World Schoolhouse. Education reimagined. Twelve. doi:https://doi.org/10.1111/edth. 12072

Kuo, Y. C., Walker, A. E., Schroder, K. E. E., \& Belland, B. R. (2014). Interaction, Internet self-efficacy, and self-regulated learning as predictors of student satisfaction in online education courses. The Internet and Higher Education., 20, 35-50. doi:https://doi.org/10.1016/jiheduc.2013.10.001

Nurhasanah, S., \& Sobandi, A. (2016). Minat belajar sebagai determinan hasil belajar siswa. Jurnal Pendidikan Manajemen Perkantoran (JPManper), 1(1), 128-135.

Palvia, S., Aeron, P., Gupta, P., Mahapatra, D., Parida, R., Rosner, R., \& Sindhi, S. (2018). Online Education: Worldwide Status, Challenges, Trends, and Implications. Journal of Global Information Technology Management.

Pangondian, R. A., Santosa, P. I., \& Nugroho, E. (2019). Faktor-Faktor Yang Mempengaruhi Kesuksesan Pembelajaran Daring Dalam Revolusi Industri 4.0. In Seminar Nasional Teknologi Komputer \& Sains (SAINTEKS), 1(1).

Rangkuti, F. (2006). Analisis SWOT Teknik Membedah Kasus Bisnis. Jakarta: PT. Gramedia Pustaka Utama.

Rusdiana, E., \& Nugroho, A. (2020). Respon Mahasiswa Pada Pembelajaran Daring Bagi Mahasiswa Mata Kuliah Pengantar Hukum Indonesia UNESA. Integralistik, , 31(1), 112.

Stein, R. A. (2020). COVID-19 and rationally layered social distancing. International Journal of Clinical Practice, 7, 4(7), e13501.

Sun, S. Y. H. (2014). Learner perspectives on fully online language learning. Distance Education, 35(1), 18-24. doi:https://doi.org/10.1080/01587919.2014.891428

Wicaksono, S. R. (2012). Kajian Pembelajaran Online Berbasis Wiki Di Lingkup Perguruan Tinggi. Journal of Education and Learning, , 6(1), 51-58.

Fitriyani, Y., Fauzi, I., \& Sari, M. (2020). Motivasi Belajar Mahasiswa Pada Pembelajaran Daring Selama Pandemik Covid-19. Jurnal Kependidikan: Jurnal Hasil Penelitian dan Kajian Kepustakaan di Bidang Pendidikan, Pengajaran dan Pembelajaran, 6(2), 165-175. doi:https://doi.org/10.33394/jk.v6i2.2654

Zhang, D., Zhao, J. L., Zhou, L., \& Nunamaker, J. F. (2004). Can e-learning replace classroom learning? Communications of the ACM. doi:https://doi.org/10.1145/986213.986216 